\title{
Assessing Mainland Chinese Tourists' Satisfaction with Hong Kong Using Tourist Satisfaction Index ${ }^{1}$
}

\author{
Haiyan Song, ${ }^{\mathrm{a}, 2}$ Gang Li, ${ }^{\mathrm{b}}$ Robert van der Veen ${ }^{\mathrm{a}}$ and Jason L. Chen ${ }^{\mathrm{a}}$ \\ ${ }^{a}$ School of Hotel and Tourism Management, The Hong Kong Polytechnic University, Hung \\ Hom, Kowloon, Hong Kong, China \\ ${ }^{\mathrm{b}}$ Faculty of Management and Law, The University of Surrey, Guildford, Surrey, United \\ Kingdom
}

\begin{abstract}
The purpose of this study is to test a two-step tourist satisfaction index framework empirically. The first step estimates sectoral-level satisfaction indexes based on a structural equation model, and the second obtains an overall tourist satisfaction index by conducting second-order confirmatory factor analysis. This study acts as a pilot test of the theoretical framework based on three selected tourism-related sectors in Hong Kong. The results indicate that mainland Chinese tourists are most satisfied with the hotel sector in Hong Kong, followed by the retail sector, and least satisfied with local tour operators. The aggregate tourist satisfaction index for Hong Kong is 74.04 out of 100. The results of this study have important practical implications for long-term destination management.
\end{abstract}

Keywords: Tourist satisfaction index, structural equation modelling, partial least squares, Hong Kong.

\footnotetext{
${ }^{1}$ The article should be cited as follows: Song H, Li G, Van Der Veen R, Chen JL. (2011). Assessing Mainland Chinese Tourists' Satisfaction with Hong Kong Using Tourist Satisfaction Index. International Journal of Tourism Research, 13 (1), pp. 82-96. DOI: 10.1002/jtr.801

${ }^{2}$ Corresponding author: The authors would like to acknowledge the financial support of The Hong Kong Polytechnic University (Grant No.: 1BB61).
} 


\section{INTRODUCTION}

Tourist satisfaction has become an increasingly important topic for destination management organisations because it serves as a reliable yardstick to assess overall performance. A good understanding of tourist satisfaction levels, as well as the dynamic changes in these levels, benefits not only the service industries that focus on inbound tourism, but also the government regulators and private investors that have a vested interest in the development of a high-quality tourism infrastructure. Improving tourist satisfaction levels is likely to contribute to an enhanced reputation for both service providers and the destination as a whole. In addition, consumer studies indicate that an improvement in these satisfaction levels may contribute to increased consumer loyalty, reduced price elasticities, a lower cost of future transactions and improved productivity (Anderson et al., 1994; Swanson and Kelley, 2001). Government agencies and scholars have launched a number of tourist satisfaction investigations at the destination level, but there are a number of issues still to be resolved. For example, the link between tourist satisfaction with a particular service provider and that with the destination as a whole remains unknown. As a result, it is unclear which particular sector(s) contributes the most or the least to tourists' overall satisfaction. Furthermore, there has been no continuous evaluation system that facilitates the assessment of tourist satisfaction on a regular basis at both the sectoral and destination levels. Thus, the dynamic nature of tourist satisfaction with a destination based on individual sectors has been largely ignored. An aggregated evaluation method is necessary because tourism is an integrated system that comprises a number of sectors, such as accommodation, catering, transport, visitor attractions, travel intermediaries (tour operators and travel agencies), retailing and public services (e.g., the police and travel information centres). Every tourist will encounter one or several of these sectors when visiting a destination, and it is thus believed that sectoral satisfaction may affect his or her perceived overall satisfaction with the destination. Last but not least, academic research on tourist satisfaction is generally isolated from the industry, and most of the one-off projects that have taken place have failed to benefit ongoing tourism practice. At the same time, the tourist satisfaction surveys that have been conducted by the industry tend to be too straightforward and to lack a strong theoretical underpinning. This study aims to fill the gaps in existing research by proposing a comprehensive tourist satisfaction index (TSI) system that provides the government agencies responsible for tourism-related activities, different sectors of the tourism industry, and the general public with much needed information for decision-making and planning purposes. The study focuses on Hong Kong, where tourism is seen as one of the major economic pillars (Lo, 2006). Hong Kong Tourism Board (HKTB, 2010) figures show that visitor arrivals reached more than 29 million in 2009, a $0.3 \%$ increase over 2008 despite the global economic slowdown. Mainland China remained the largest source market, with more than 17 million arrivals, a $6.5 \%$ increase over the previous year. An evaluation of the satisfaction levels of mainland Chinese tourists is thus clearly of great practical importance for Hong Kong. 


\section{LITERATURE REVIEW}

Consumer satisfaction has been widely explored by scholars and practitioners over the past three decades. A number of methodological approaches to the measurement of such satisfaction have been developed, but no consensus has yet been reached on the best approach. The marketing literature has mainly focused on two opposing schools of thoughts: the American school led by Parasuraman et al. (1985) and the Nordic school led by Grönroos (1984). The former regards consumer satisfaction as a reflection of either positive or negative gaps between consumers' initial expectations and their perceptions of a product or service's performance, whereas the latter considers consumer satisfaction to be "an outcome of the actual quality of performance and its perception by consumers" (Kozak and Rimmington, 1999, p. 261). Both theories have received a considerable amount of criticism. One major shortcoming of the expectation-perception approach is that customers' retrospective expectations may be altered by the receipt of further information on the product or service in question, and it is thus difficult to measure their actual repurchase expectations (Yüksel and Yüksel, 2001). The absence of the expectation variable in the performance-only model, however, makes it "impossible to interpret high levels of customer satisfaction as the results of low expectations or superior quality of service provider" (Fuchs and Weiermair, 2004, p. 215). Measuring expectations provides additional information to determine the optimum level of performance, which can be used as a benchmark to improve the current service quality (Ekinci, 2002). The expectationperception concept was further refined as the expectancy-disconfirmation model by Oliver (1980), whose model comprises four elements: expectation, perceived performance, disconfirmation and satisfaction. Consumers have expectations of a product or service before purchasing it, and they then compare its actual performance with those expectations. If their expectations are exceeded, then positive disconfirmation is reached, which, in turn, leads to consumer satisfaction and willingness to purchase, and vice versa. Consumer satisfaction research has also introduced the importance-performance model, equality theory and norm theory. The importance-performance model developed by Cohen et al. (1972) defines an individual's attitude as his or her importance-weighted evaluation of the performance of specific dimensions of a product or service. Oliver and Swan (1989) argue that consumer satisfaction can be regarded as the relationship between the costs and benefits associated with the product or service purchased, with price, time and effort the key factors influencing such satisfaction. LaTour and Peat (1979) introduced norm theory, according to which "norms serve as reference points for judging the product, and dissatisfaction comes into play as a result of disconfirmation relative to these norms" (Yoon and Uysal, 2005, p. 47). Sirgy (1984) replaced "norm" with "ideal standard" to propose the congruity model, which suggests that consumer satisfaction depends on the comparison of a product or service's perceived performance with a hypothetical ideal product or service. A comprehensive review of the aforementioned approaches can be found in Oh and Parks (1997).

A number of approaches have been adopted in the tourism literature to examine tourist satisfaction, for example, the expectation-perception gap model (Duke and Persia, 1996), the expectancy-disconfirmation model (Pizam and Milman, 1993), the performance- 
only model (Pizam et al., 1978) and the congruity model (Chon, 1990, 1992; Chon and Olsen, 1991). Of these, the expectancy-disconfirmation framework has been given the most attention and been applied in many tourist satisfaction studies. When it comes to measuring tourists' evaluation of their experience, however, expectancy-disconfirmation is just one of several possible benchmarks that tourists use to rate their overall satisfaction. The lack of agreement amongst existing approaches and the complexity of tourist satisfaction issues led Yoon and Uysal (2005) to suggest that such satisfaction should be investigated in multiple dimensions and that a model that integrates alternative approaches would be more effective in its assessment.

Tourism researchers have been interested in measuring both overall tourist satisfaction with a particular destination (e.g., Alegre and Cladera, 2006; Kozak, 2001; Yu and Goulden, 2006) and tourist satisfaction with a specific service encounter, such as that in the accommodation sector (Hsu et al., 2003; Saleh and Ryan, 1992), restaurants (Chadee and Mattsson, 1996), attractions (Dorfman, 1979), travel agencies (Leblanc, 1992), packaged tours (Hsu, 2000, 2003; Pizam and Milman, 1993) and retail shops (Reisinger and Turner, 2002). Most assessments of tourist satisfaction within a particular destination are based on multi-attribute scales that cover a variety of service components and facilities. Factor analysis is the typical tool employed to categorise these attributes for further regression or correlation analysis between the categories and overall tourist satisfaction. However, these categories do not necessarily refer to a particular sector within the broader tourism industry. For example, "price level" covers all sectors that a tourist comes across in a destination, and it is impossible to conclude which sector's prices contribute most significantly to overall tourist satisfaction. The findings of this type of research are thus unable to provide administrators with clear guidance on the most effective destination management policies or strategies. Another problem with existing tourist satisfaction studies is that most have overlooked the dynamic nature of such satisfaction. Long-term aspects of the satisfaction process, such as attitude changes, have also been ignored (Oh and Parks, 1997). Most academic tourist satisfaction studies employ one-off surveys, and no system for the continuous assessment of tourist satisfaction is currently in place. The ability to report the dynamics of tourist satisfaction over time and across different source markets or service sectors thus remains lacking.

Consumer satisfaction assessments by scholars, the industry and government representatives have led to the establishment of national and regional consumer satisfaction indexes. The Swedish customer satisfaction barometer, for example, was introduced in 1989 (Fornell, 1992), followed a few years later by the American customer satisfaction index (Fornell et al., 1996). Other national and regional indexes include the Norwegian customer satisfaction barometer (Andreassen and Lervik, 1999) and the European customer satisfaction index, which covers 11 countries in the European Union (Eklöf and Westlund, 2002). Apart from slight modifications, all of these indexes or barometers have similar features to the American customer satisfaction framework, which is an evolution of the original Swedish model. They all focus on domestically purchased and consumed products and services. Although a few studies have included tourism-related sectors, the respondents have tended to be locals using domestic facilities that can serve both residents and tourists. 
For example, Knutson et al. (2003) report on the lodging section of the American consumer satisfaction index. They examine six hotel brands in the United States merely by comparing the mean values of three satisfaction items. Although their study discusses the framework of the index, its lacks interpretation of the structural relationships within it. In addition, their sample was drawn from domestic households, and their respondents can thus be classified as domestic tourists. The domestic tourism sector is an important one that is worthy of study, but many destinations are also interested in increasing the share of foreign currencies on their balance sheet. This study thus examines inbound tourists' satisfaction with a destination. Also deserving of attention is the link between the micro and macro levels of consumer satisfaction. Chan et al. (2003) developed the Hong Kong consumer satisfaction index, which provides useful guideline on linking these levels. Their structure is particularly relevant for this study because they initially developed product-level indexes and then aggregated these indexes to obtain an overall consumer satisfaction index that represents the overall quality of goods and services sold in Hong Kong as evaluated by local consumers. To achieve their aggregate index, Chan et al. (2003) employed a weighting system that assigns different weights to different types of products. To calculate these weights accurately, household expenditures on different consumer goods are adjusted by the consumer price index (CPI). However public goods and services are not linked to the CPI, and therefore they are not included in the consumer satisfaction index developed by Chan et al. (2003). The CPI weighting scheme is not applicable to public services, and it is thus inappropriate for the development of a TSI because tourists may make use of the services of the police, immigration, parks and museums, and their level of satisfaction with these public services may contribute substantially to their satisfaction assessment of the destination as a whole. An overall TSI that excludes free-of-charge service sectors cannot truly reflect the overall tourist experience in a destination. This study thus proposes a more appropriate weighting scheme for the overall TSI discussed in the next section.

\section{METHODOLOGY}

This section illustrates the proposed two-step index system for evaluating tourist satisfaction. The first step evaluates such satisfaction at the sectoral level. At this level, various tourism-related sectors can be included, such as accommodation, restaurants, transport, attractions, tour operators, retail shops and public services (e.g., immigration and the police). Different from the many tourist satisfaction studies that employ direct measurement, tourist satisfaction in this study is measured as a latent variable that is associated with three indicators: overall satisfaction, confirmation of expectations and comparison with ideal. As a result, the satisfaction construct integrates the performanceonly approach, the expectancy-disconfirmation approach and norm theory. Bagozzi et al. (1981) and Fornell et al. (1996) suggest that if a latent variable reflects the causal relationship between the service attributes within a system (called a nomological net), then the validity of that variable is ensured. The calculation of the sectoral TSI is derived from a structural equation model (see Figure 1) in which tourist satisfaction is evaluated in respect to its antecedents and consequences. This model generates the weights of the three satisfaction measures and provides information on the structural relationships. 


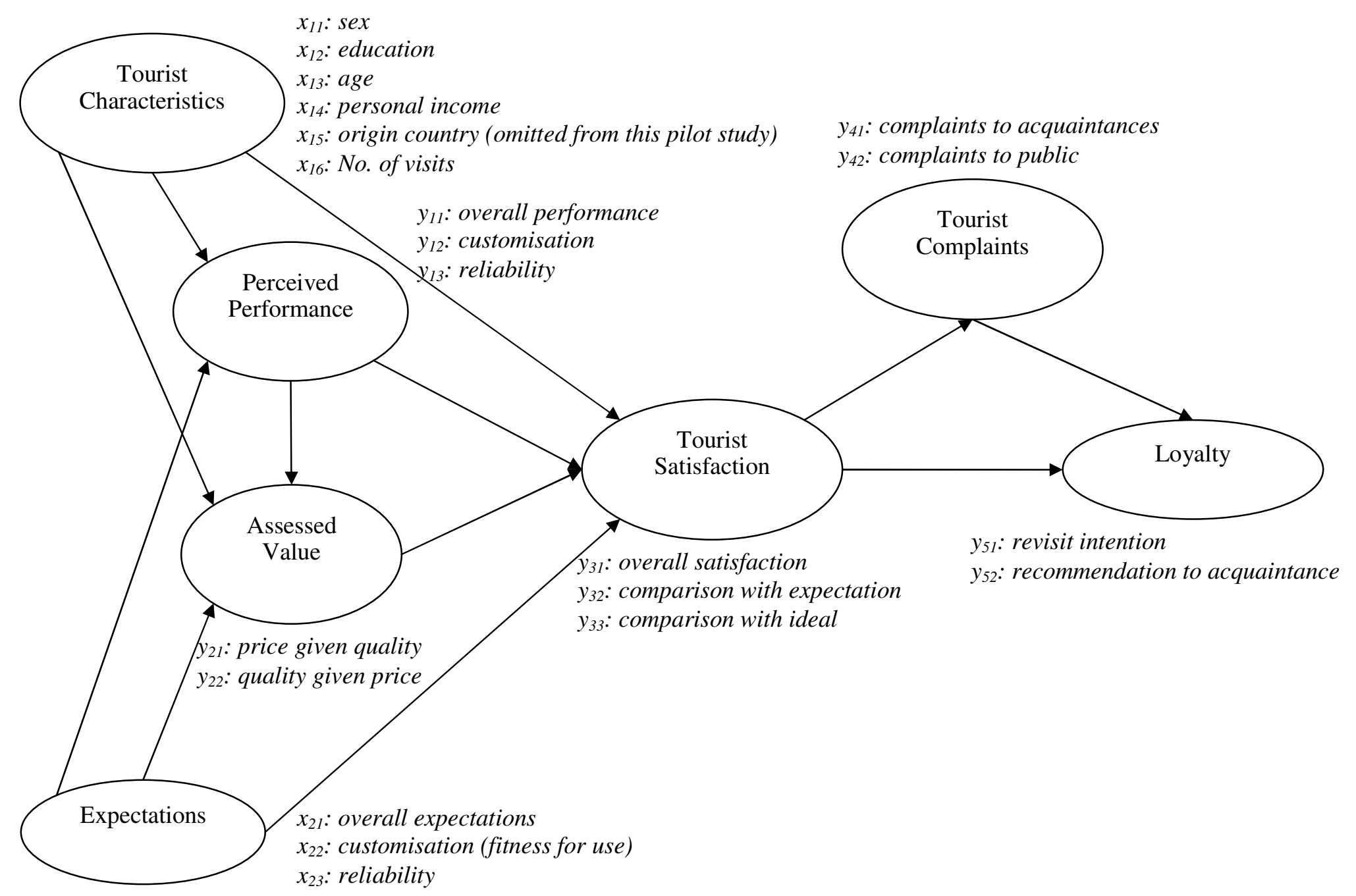

Figure 1. The hypothesised sectoral-level tourist satisfaction index model 
All five of the model's constructs are measured by multiple items. Expectations and perceived performance are incorporated into the hypothesised model as important antecedents of tourist satisfaction. Another factor that influences such satisfaction is the assessed value of the services encountered in a destination. This factor captures tourists' assessment of service quality relative to the price paid (for private goods and services) or the time spent (for public services). In addition, the inclusion of tourist characteristics in the model allows tourist satisfaction levels to be distinguished by demographic background (Chan et al., 2003; Lancaster, 1971). Complaint intentions and loyalty are included as two formative consequences of tourist satisfaction. Based on exit-voice theory (Hirschman, 1970), it is believed that an increase in satisfaction is likely to decrease tourists' intention to complain and to increase their destination loyalty. To investigate such loyalty, the proposed model measures revisit intention and positive word of mouth, both of which are desirable outcomes for tourism policy-makers in terms of evaluating destination competitiveness. The indicators of each construct are presented in Figure 1. All of the manifest variables are measured on 11-point rating scales that range from -5 for "poor" to +5 for "excellent". Such a bipolar conceptualisation of the dimensions (Schwarz et al., 1991) is believed to be more sensitive to the detection of differences (Bandura, 2006). The use of 11-point scales and multiple indicators can also help to reduce the negative skewness that is commonly associated with the distributions of ratings for satisfaction-related indicators (Fornell, 1992; Fornell et al., 1996). Such scales and indicators are commonly used in consumer satisfaction surveys (e.g., Chan et al., 2003). The inclusion of formative measures allows the employment of the components-based approach known as partial least squares (Chin and Gopal, 1995; Cohen et al., 1990; Fornell and Bookstein, 1982) to estimate the structural equation model. In this soft modelling approach, the internal structural relationships amongst the constructs are explained by a set of linear regression equations known as latent structural equations, whilst the external relationship between each construct and its indicators is described by factor analysis equations, also known as measurement equations (Chan et al., 2003; Fornell and Cha, 1994; Fornell et al., 1996). As various causal relationships are integrated in the model, recommendations can be made for the evaluation or revision of particular tourism policies to improve the competitiveness of the destination under study.

The sectoral TSI is computed using the model-implied weights $\left(\omega_{31}, \omega_{32}\right.$ and $\left.\omega_{33}\right)$. For convenience in calculating the indexes, the original -5 to +5 scales were transformed into a 0 to 10 scale format. The sectoral TSI is then calculated as:

$$
\text { Sub-TSI }=\frac{\omega_{31} \bar{y}_{31}+\omega_{32} \bar{y}_{32}+\omega_{33} \bar{y}_{33}}{\omega_{31}+\omega_{32}+\omega_{33}} \times 10
$$

where $\bar{y}_{31}, \bar{y}_{32}$ and $\bar{y}_{33}$ are the sample means of the three satisfaction indicators. It should be noted that applying the same weighing scheme to each respondent's individual scores on the three indicators means that a satisfaction index can be assigned to each corresponding tourist. Such an individual satisfaction index variable can further facilitate market segmentation analysis. In addition, the sectoral TSI framework is readily applicable to the product level (e.g., a hotel) once a sub-sample has been extracted based on the name of the 
service provider encountered by a respondent. Cross-product comparisons within a service sector are thus possible, although such analysis is beyond the scope of the current study.

The second step in the proposed satisfaction evaluation system is to estimate the overall TSI for the destination based on the sectoral TSI results obtained in the first step. The weights for the overall TSI are retrieved by employing a second-order confirmatory measurement model. Second-order confirmatory factor analysis provides a structure by which the first-order factors become manifest variables of the second-order factors. Such analysis explicates the pattern of constructs assumed to underlie the variables, in other words, how each first-order factor (sector) contributes to the higher-order factor (destination). In this model (see Figure 2), the constructs are formed by respondents' level of satisfaction with individual sectors, each of which is measured by the three satisfaction items. In turn, the factor loadings indicate the contributions made by sectoral satisfaction to overall satisfaction, and hence they are adopted as the weights for estimating the overall TSI. Given the objective weights obtained from the second-order confirmatory factor analysis of destination satisfaction, this procedure has a strong scientific basis, which in turn guarantees the robustness of the overall TSI estimation.

The weights are then introduced in the second equation to calculate the overall TSI. As explained above, tourist satisfaction within a particular tourism sector equals the weighted average of the mean values of its three satisfaction indicators $\left(\bar{y}_{31}, \bar{y}_{32}\right.$ and $\left.\bar{y}_{33}\right)$ multiplied by a scaling constant of 10 . Thus, each TSI is expressed on a $0-100$ scale. The higher tourists' average scores on the satisfaction questions, the greater the calculated sectoral TSI. The overall TSI, as the weighted average of the sectoral TSIs, is given in Equation (2), where the $\gamma_{i}$ 's are the factor loadings derived from the confirmation measurement model for the overall TSI calculation.

$$
\text { Overall TSI }=\frac{\sum_{i=1}^{m} \gamma_{i} \text { Sub-TSI }_{i}}{\sum_{i=1}^{m} \gamma_{i}} .
$$

The proposed two-step TSI framework has the following four distinct advantages.

1) Tourist satisfaction within each individual sector is measured by the same set of indicators. Thus, the TSIs at the sectoral level are directly comparable.

2) The overall TSI is computed on the basis of the sectoral TSIs using a weighting scheme that is determined by the tourists' own evaluations. As a result, free-of-charge and other public services can be included in its compilation.

3) Tourist satisfaction assessment at both the sectoral and destination levels can be estimated, thereby providing more comprehensive information for destination management.

4) The proposed TSI system can be used repeatedly to capture the dynamics of tourist satisfaction, thus reflecting changes in a destination's competitiveness over time. 


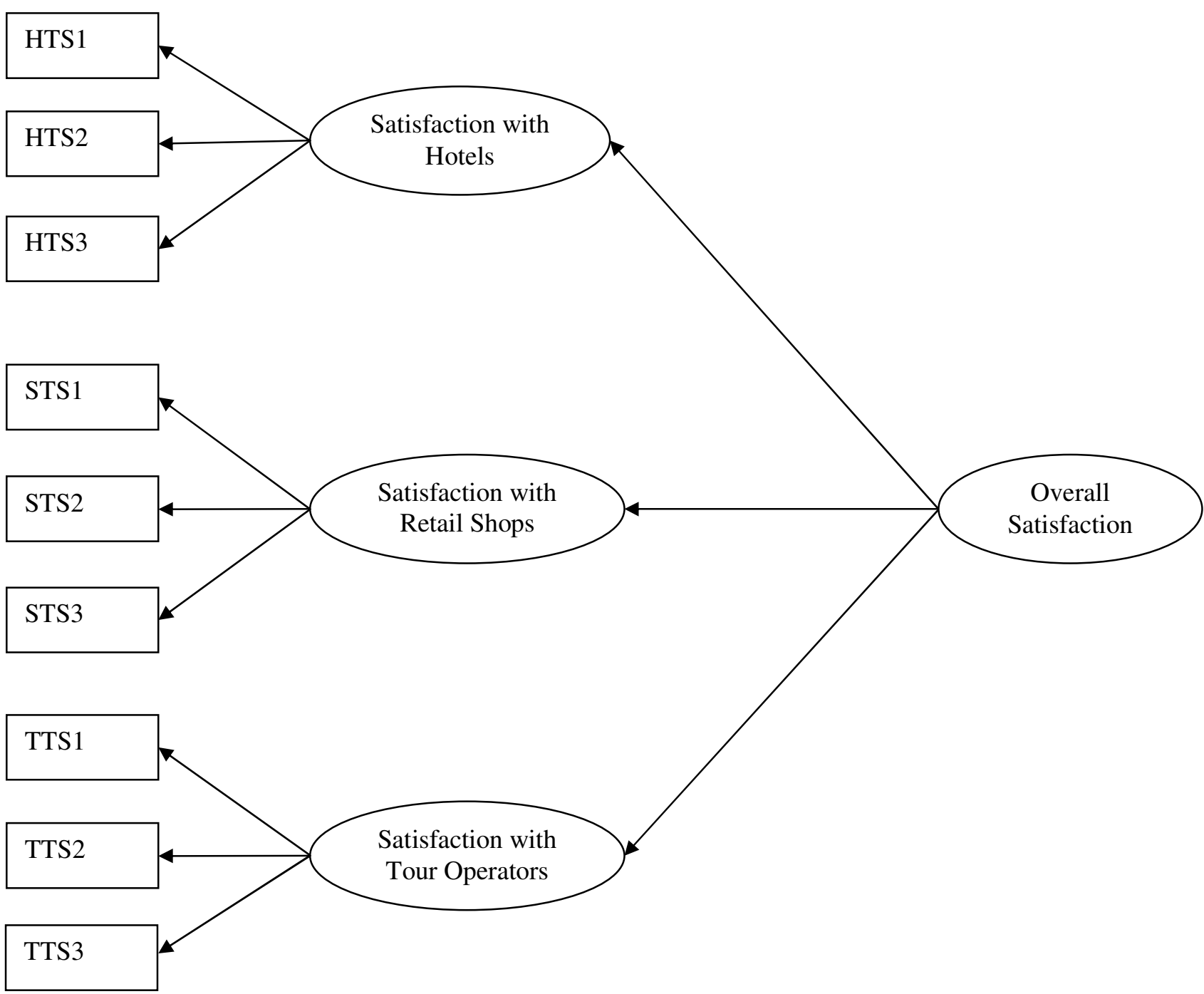

Figure 2. The overall tourist satisfaction index model

Note: HTS, STS and TTS refer to the measurement indicators of tourist satisfaction with hotels, retail shops and tour operators, respectively. 


\section{RESULTS}

Hong Kong was selected as the destination for this investigation because of its status as a well-developed, mature tourism destination. Kozak (2001) has found that the relationship between overall satisfaction and loyalty is stronger for mature destinations than for less familiar destinations. Loyalty is an important outcome of the current framework, as well as a desirable strategic result for many tourism operators and regulators. The mainland Chinese source market is the target population in this pilot study, and any competitive advancement in this segment should be of interest to both the government and service industry in Hong Kong. Because the primary purpose of this study was to test the validity and reliability of the proposed two-step framework, only three key tourism-related sectors were included in the survey, hotels, local tour operators and retail shops, and, accordingly, only these sectors are included in the computation of the overall TSI to demonstrate the aggregation method. A face-to-face street intercept survey employing a self-administered questionnaire facilitated the data collection, which took place over two days in November 2008, and a convenience sampling method was adopted at a variety of locations in Hong Kong. The final sample included 279 valid responses. Respondents' details are presented in Table 1.

Table 1. Profile of survey respondents

\begin{tabular}{|c|c|c|c|}
\hline Variable & $\%$ & Variable & $\%$ \\
\hline Sex & \multicolumn{2}{|r|}{ Education } & \\
\hline Male & 51.4 & No formal education & 0.8 \\
\hline \multirow[t]{4}{*}{ Female } & 48.6 & Primary/elementary school & 0.8 \\
\hline & & Secondary/high school & 23.5 \\
\hline & & College/university & 66.8 \\
\hline & & Postgraduate & 8.1 \\
\hline Age & \multicolumn{2}{|r|}{ Number of past visits } & \\
\hline $16-25$ & 21.43 & 0 & 39.2 \\
\hline $26-35$ & 34.92 & 1 & 31.5 \\
\hline $36-45$ & 20.24 & 2 & 9.1 \\
\hline $46-55$ & 18.25 & 3 & 5.6 \\
\hline $56-65$ & 4.37 & 4 & 4.3 \\
\hline$\geq 66$ & 0.79 & $\geq 5$ & 10.3 \\
\hline \multicolumn{4}{|c|}{ Monthly Income (Renminbi) } \\
\hline$<1,000$ & 3.9 & & \\
\hline $1001-3000$ & 12.0 & & \\
\hline $3001-6000$ & 17.2 & & \\
\hline $6001-7500$ & 18.0 & & \\
\hline $7500-9000$ & 14.6 & & \\
\hline$\geq 9001$ & 4.7 & & \\
\hline No regular income & 3.9 & & \\
\hline
\end{tabular}

Note: All percentages are calculated on the basis of valid responses.

The SmartPLS 2.0 M3 software program (Ringle et al., 2005) was employed for the first step of the analytical procedure. As tourist surveys are usually subject to non-responses, missing values $(<10 \%)$ were imputed before estimating the model. The expectation- 
maximisation algorithm recommended in LISREL 8.80 was adopted to replace the missing values with estimates (Schumacker and Lomax, 2004). Model validity was assessed by determining the significance of the model's estimated path coefficients using the bootstrapping option. Bootstrapping is a resampling technique employed to assign measures of accuracy to statistical parameters in the form of $t$-values. Most of the literature (e.g., Temme et al., 2006) recommends bootstrapping over blindfolding or jack-knifing as a resampling method. Furthermore, Chernick (2007) points out that bootstrap bias correction can yield a nearly unbiased estimator that thus has a far smaller degree of variance than the leave-one-out estimator. As a result, this method is superior in terms of the mean square error. Estimating these statistics depends on the number of resamples in the observed dataset. Tenenhaus et al. (2005) suggest setting this number at 200 for more reasonable standard error estimates.

The estimates show that approximately half of the structural paths (six or seven out of twelve) in the hypothesised model are significant and in the predicted direction. However, none of the path coefficients between the tourist characteristics construct and its consequences is significant. The insignificant analysis of variance (ANOVA) and $t$-test results between different demographic groups for the related constructs provide further evidence to indicate that these characteristics have little influence on tourist satisfaction, perceived performance or assessed value. ${ }^{1}$ Accordingly, this construct was removed from the final model. The remaining path coefficients are highly consistent with the hypothesised model in terms of significance, with most of the paths in the final model reaching a statistically significant level (six or seven out of nine across all sectors). Most of the significant path coefficients are close to or well above 0.30 (see Figures 3-5), which indicates that the final model has strong predictive power and again verifies the insignificant effect of tourist characteristics. Caution requires, however, that the final model be carefully tested again in the main survey with a larger sample that covers different source markets and different service sectors.

In terms of discriminant validity, the average variances extracted for all three of the sectors examined are consistently above $70 \%$ in the hypothesised model and above $69 \%$ in the final model (see Table 2), both of which are higher than the critical value of $50 \%$ recommended by Fornell (1992) and Fornell and Larcker (1981). We can thus conclude that each reflective dimension and its respective indicators are highly correlated (Chan et al., 2003). Moreover, the high degree of consistency between the hypothesised and final models once again confirms the insignificance of the tourist characteristics construct and justifies the model reduction. The reliability test suggests that all indicators of the reflective constructs (satisfaction, perceived performance, expectations and assessed value) are reliable because all of the standardised indicator loadings for the three sectors are positive and significant ( 0.73 to 0.96$)$.

\footnotetext{
${ }^{1}$ Neither the parameter estimates of the hypothesised model nor the ANOVA and $t$-test results are presented in this paper because of space constraints, but they are available from the authors upon request.
} 


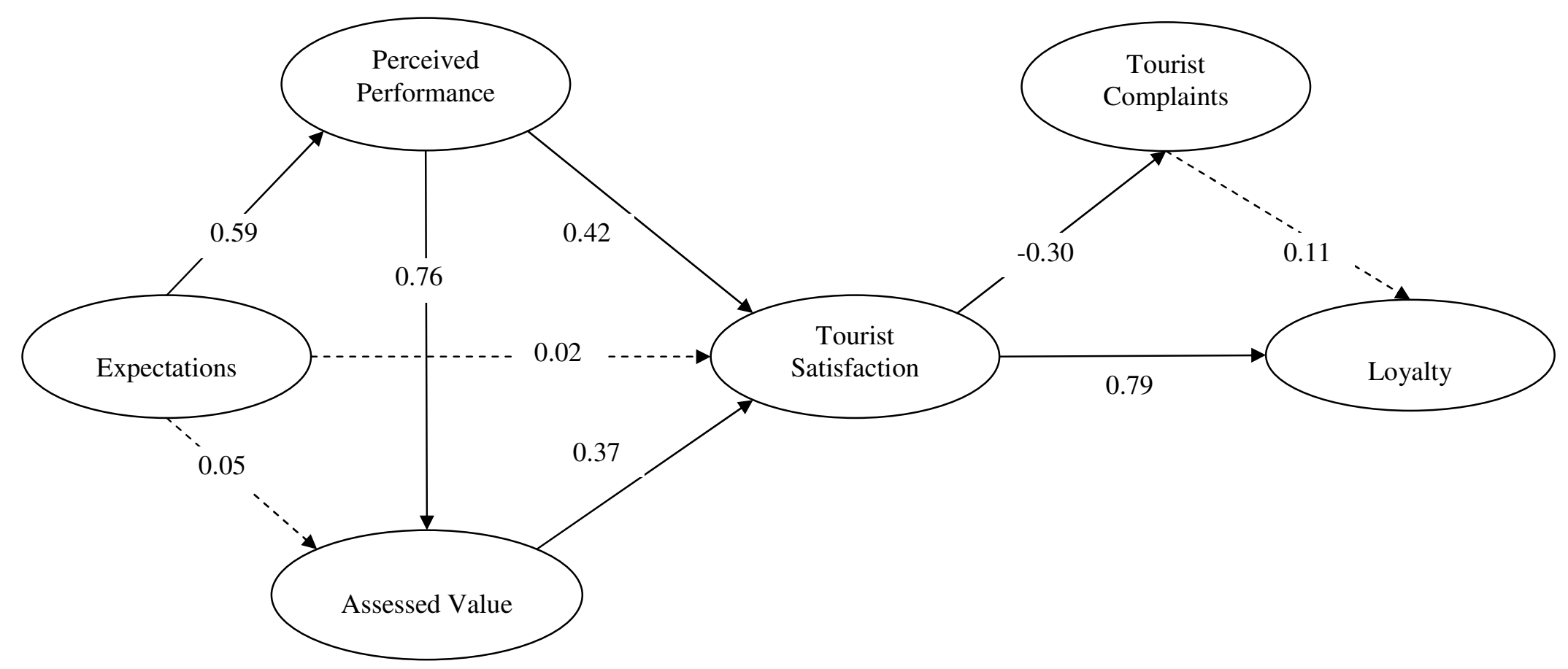

Significant at the 0.05 level

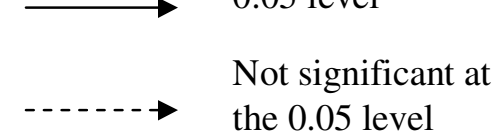

Figure 3. Path coefficients of final sectoral-level model - hotels 


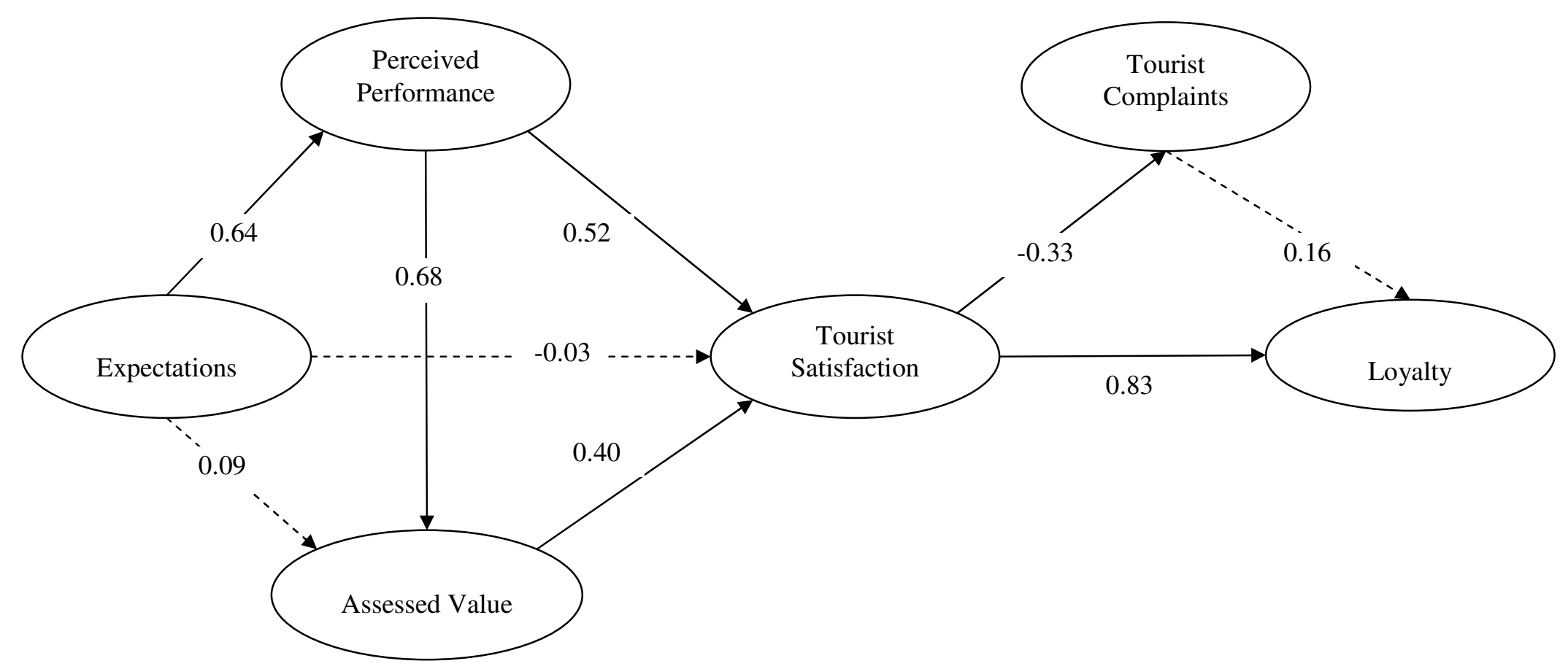

Significant at the 0.05 level

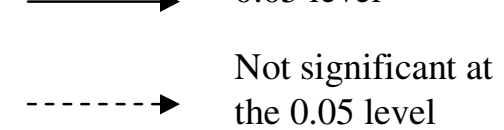

Figure 4. Path coefficients of final sectoral-level model - retail shops 


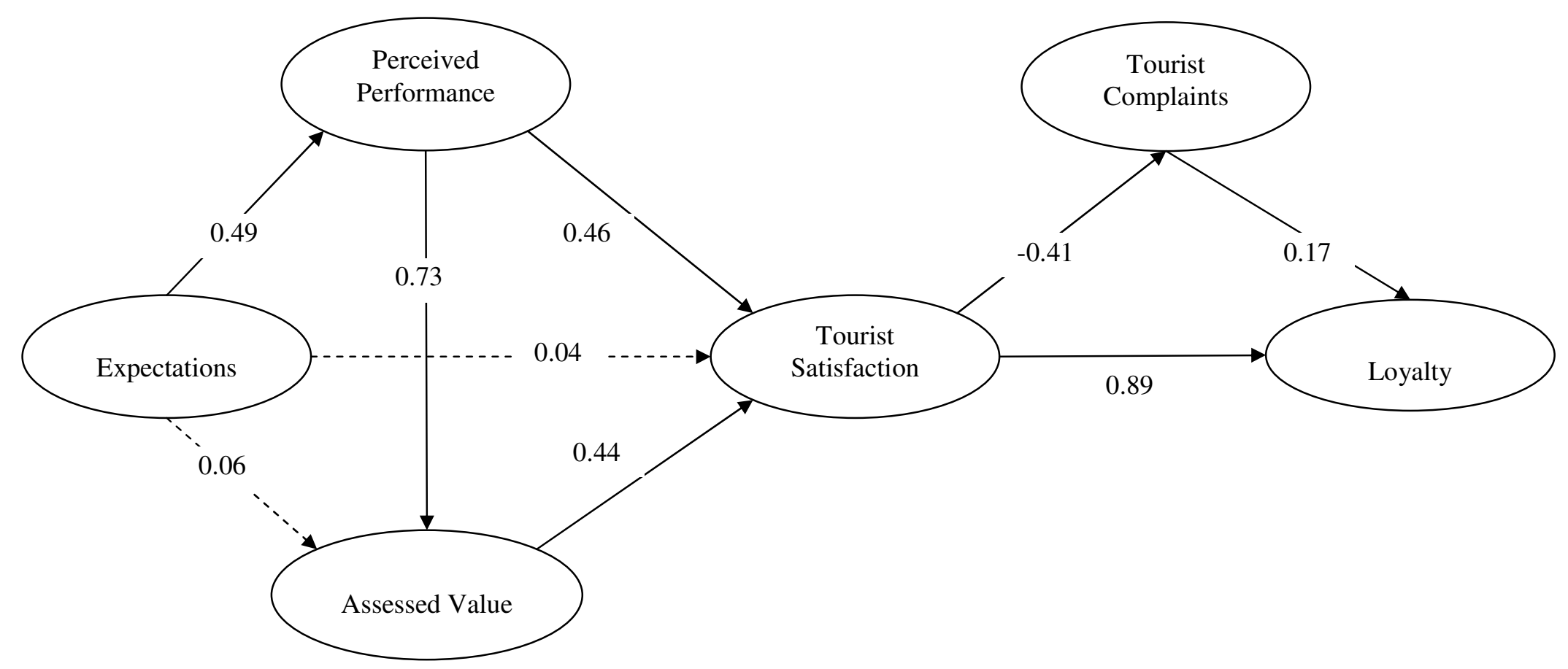

Significant at the 0.05 level

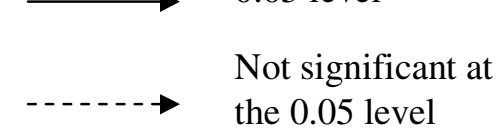

Figure 5. Path coefficients of final sectoral-level model - tour operators 
These results mean that the corresponding error variances are small, and the manifest variables are thus reliable indicators. In addition, a substantial degree of internal consistency is evidenced by the high Cronbach's alphas, which range from 0.77 to 0.95 (see Table 3).

Table 2. Average variance extracted

\begin{tabular}{llcccc}
\hline Model & Sector & $\begin{array}{c}\text { Satisfaction } \\
(\%)\end{array}$ & $\begin{array}{c}\text { Performance } \\
(\%)\end{array}$ & $\begin{array}{c}\text { Expectations } \\
(\%)\end{array}$ & $\begin{array}{c}\text { Value } \\
(\%)\end{array}$ \\
\hline Hypothesised model & Hotels & 70 & 81 & 87 & 88 \\
& Tour operators & 75 & 89 & 86 & 90 \\
& Shops & 76 & 85 & 85 & 90 \\
\hline Final model & Hotels & 69 & 79 & 85 & 88 \\
& Tour operators & 75 & 91 & 83 & 90 \\
& Shops & 76 & 85 & 85 & 92 \\
\hline
\end{tabular}

Table 3. Cronbach's alphas

\begin{tabular}{lcccc}
\hline Sector & Satisfaction & Performance & Expectations & Value \\
\hline Hotels & 0.77 & 0.86 & 0.91 & 0.86 \\
Tour operators & 0.84 & 0.95 & 0.90 & 0.89 \\
Shops & 0.84 & 0.91 & 0.91 & 0.91 \\
\hline
\end{tabular}

Note: The results are the same for both the hypothesised and final models.

The $R^{2} \mathrm{~s}$ for the structural equations used to predict tourist satisfaction are quite high for all three sectors (see Table 4). Those employed to predict performance, assessed value and loyalty also demonstrate a reasonable degree of explanatory power, except for the complaints construct. This result is consistent with the suggestion of both Chan et al. (2003) and Johnson et al. (2001) that the complaints construct has little effect on either satisfaction or loyalty. Possible explanations for the low $R^{2}$ for this construct are the ineffectiveness of the complaint management system (Johnson et al., 2001) and many respondents' lack of an intention to complain. In addition, research has found that Asians, including the Chinese, Japanese and Koreans, tend to keep silent instead of expressing dissatisfaction to save face and to avoid embarrassing vendors (Ap, 2000).

Table 4. Multiple $R$-squares $\left(R^{2}\right)$

\begin{tabular}{llccccc}
\hline Model & Sector & Satisfaction & Performance & Value & Complaints & Loyalty \\
\hline Hypothesised model & Hotels & 0.59 & 0.36 & 0.66 & 0.11 & 0.57 \\
& $\begin{array}{l}\text { Tour } \\
\text { operators }\end{array}$ & 0.75 & 0.21 & 0.58 & 0.11 & 0.69 \\
& Shops & 0.68 & 0.40 & 0.50 & 0.08 & 0.62 \\
\hline Final model & Hotels & 0.57 & 0.34 & 0.53 & 0.09 & 0.59 \\
& Tour & 0.76 & 0.24 & 0.58 & 0.17 & 0.70 \\
& $\begin{array}{l}\text { operators } \\
\text { Shops }\end{array}$ & 0.69 & 0.41 & 0.54 & 0.11 & 0.62 \\
\hline
\end{tabular}




\section{Relationships amongst satisfaction and its antecedents}

The estimated paths from performance to satisfaction and from performance to assessed value appear to be supported, and are in the positive direction across all sectors. The implication is that boosting the service performance of hotels, retail shops and tour operators is likely to enhance tourists' satisfaction and the assessed value of the services received in these sectors. For instance, a one-point increase in hotel service performance increases tourist satisfaction by 0.42 of a point and perceived value by 0.76 of a point (see the corresponding path coefficients in Figure 3). As a result, tourists may perceive that they obtain good value for money only if they are satisfied with the service performance. The same applies to the relationship between expectations and performance, which is in line with previous research implying that increasing consumer expectations may enhance the assessed performance of a product (Johnson et al., 1995). The path from expectations to assessed value and that from expectations to satisfaction were not confirmed, similar to the findings of other studies, as highlighted by Chan et al. (2003). These studies report that increasing expectations may have no or only a weak impact on satisfaction (Johnson et al., 1995; Johnson and Fornell, 1991) or may even lead to a decrease in satisfaction (Yi, 1990). The path between assessed value and satisfaction was in the predicted positive direction and significant for all sectors, thus indicating that if tourists perceive good value for money, then their satisfaction levels are likely to be enhanced.

\section{Relationships amongst satisfaction and its consequences}

The complaints and loyalty constructs were proposed as formative, and the sign structures of their estimated indicator weights or loadings are consistent across sectors. The structural coefficients from satisfaction to complaints and from satisfaction to loyalty are all significant. As expected, the relationship between satisfaction and complaints carries a negative sign, thus suggesting that an increase in satisfaction leads to a decrease in complaints behaviour. The link between satisfaction and loyalty is positive, which implies that a higher level of tourist satisfaction results in increased loyalty to its respective sector. The relationship between complaints and loyalty was found to be significant only in the tour operator sector. Respondents were requested to evaluate their intentions to complain to acquaintances or to the media. The means of these two variables vary between 1.5 and 2.5 across the sectors, thus indicating that the majority of respondents had no such third-party complaint intentions.

\section{Computation of the tourist satisfaction indexes}

The calculations of the TSI for each sector are presented below. They were computed on the basis of Equation (1), with the weights obtained from the estimation results of each sector's structural equation model. 


$$
\begin{array}{lrl}
\text { Hotel TSI: } & \mathbf{7 6 . 7 8}=\frac{0.48 \times 8.11+0.30 \times 7.03+0.40 \times 7.65}{0.48+0.30+0.40} \times 10 . \\
\text { Retail Shop TSI: } & \mathbf{7 3 . 0 1}=\frac{0.43 \times 7.88+0.34 \times 6.83+0.37 \times 7.06}{0.43+0.34+0.37} \times 10 . \\
\text { Tour Operator TSI: } & \mathbf{7 2 . 8 2}=\frac{0.44 \times 7.57+0.35 \times 6.89+0.37 \times 7.31}{0.44+0.35+0.37} \times 10 .
\end{array}
$$

The calculated TSIs suggest that, of the three sectors considered, tourists are most satisfied with the hotel sector (76.78), followed by the retail sector (73.01) and the tour operator sector (72.82) on a scale ranging from 0 to 100. The TSIs for all three sectors are well above average (50.0). One explanation for the high ratings could be that many tourism and hospitality operators in Hong Kong have adopted industry-wide and/or internationally recognised service standards to ensure a high level of service. Some local businesses have published performance pledges, adopted the service accreditation proposals of the Hong Kong Association for Customer Service Excellence or the Skills Upgrading Scheme of the Education and Manpower Bureau, and/or embraced the 5S System (www.hk5sa.com) to maintain and commit themselves to high-quality service delivery and adhere to best practice standards. The leading tourism initiative in Hong Kong is the Quality Tourism Services scheme, which has been in operation since 1999 and proved to be very successful. The scheme offers tourists to Hong Kong an assurance of reliable service by formulating service quality standards for service providers. It was initiated and is maintained by the HKTB, which thus takes responsibility for the tourism industry's sustainable contribution to the Hong Kong economy. The lower satisfaction score given to local tour operators can be explained by the phenomenon of discounted tour packages. The highly discounted tour packages common in Asia result in marginal profits for operators. Tour guides are thus caught in the middle and forced to make a trade-off between low-quality lodging and restaurants and visits to highpriced souvenir and jewellery shops.

The weights for the aggregate TSI were determined by second-order confirmatory factor analysis using AMOS 17.0 (see Figure 6). In line with the interpretation in Correia et al. (2008), the retail sector was found to be the most important (0.88). When satisfaction with retail shops increases by one point, overall destination satisfaction increases by 0.88 . The tour operator sector (0.78) is the second most important for overall satisfaction, and the hotel sector (0.68) the least important.

These weights suggest that satisfaction with retail shops has the greatest impact on mainland Chinese tourists' overall satisfaction with Hong Kong as a destination, followed by satisfaction with tour operators and satisfaction with accommodation. The weights were then introduced into the second equation to calculate the overall TSI for Hong Kong. Although the model estimation is complex, the outcome is reasonably simple to interpret, as it is set to a 0100 scale:

$$
\text { Overall TSI for Hong Kong: } \mathbf{7 4 . 0 4}=\frac{0.68 \times 76.78+0.88 \times 73.01+0.78 \times 72.82}{0.68+0.88+0.78} \text {. }
$$




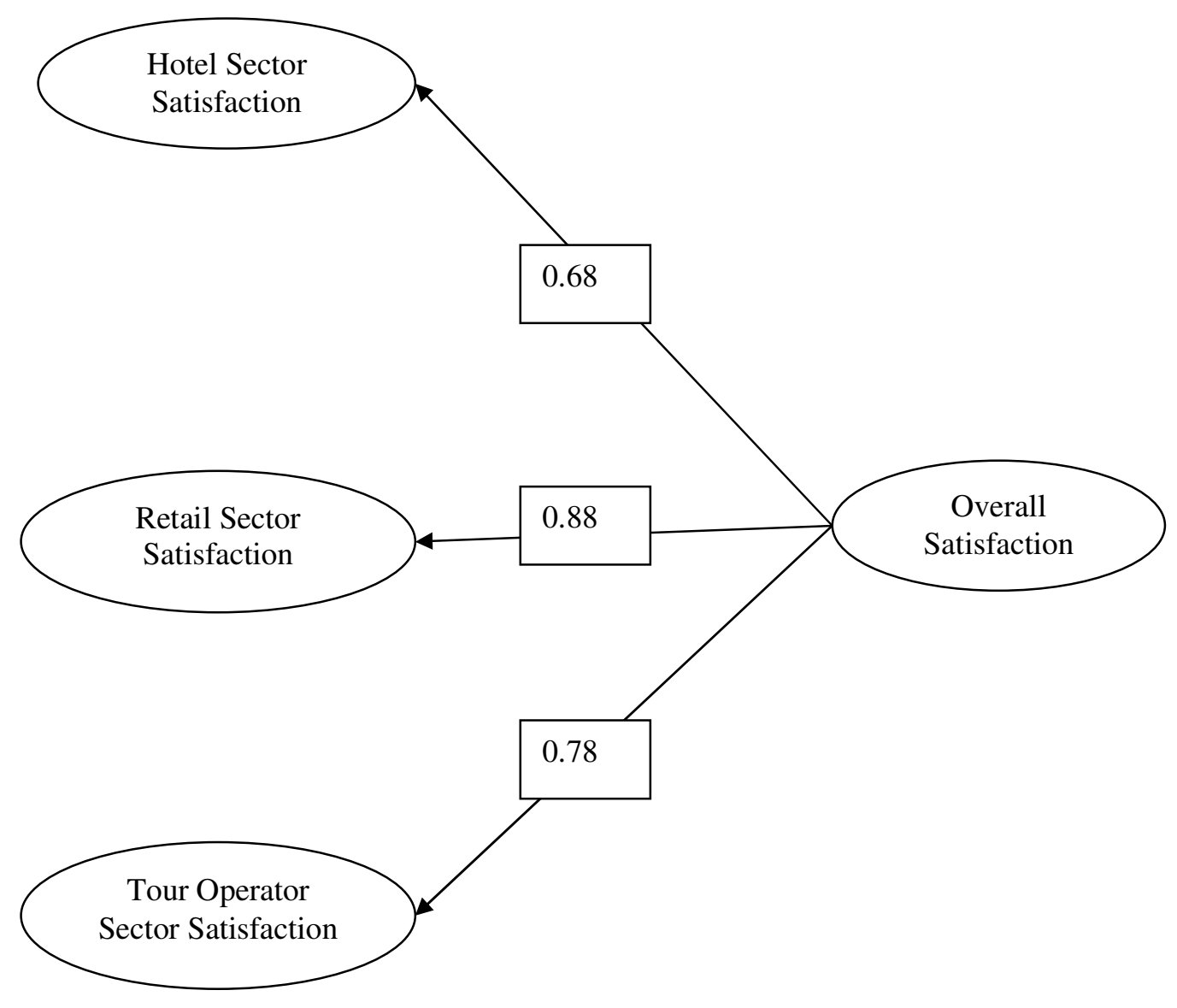

Figure 6. Weights for overall tourist satisfaction

\section{CONCLUSION}

The study reported in this paper represents the first step of a larger project to develop a TSI system that can be used to assess Hong Kong's competitiveness as an international tourism destination. The innovative two-step framework proposed herein integrates alternative approaches and captures the multiple dimensions of tourist satisfaction. It is capable of producing TSIs for individual tourism sectors, which, when combined, can be employed to estimate an overall satisfaction index. This study has analysed structural equation models for three service sectors, the hotel, retail and tour operator sectors, to test the validity and reliability of the first analytical procedure. As the paths between the tourist characteristics construct and its consequences were found to be insignificant across all three sectors, this construct was removed from the final model. Although the model requires further confirmation in the next stage of the project with a larger sample that covers different source 
markets, the pilot results reported here indicate that the framework is capable of adequately assessing both sectoral and overall satisfaction. The model can be applied to other source markets and tourism-related sectors, and can be applied repeatedly over time to capture the dynamics of tourist satisfaction. This framework has important practical implications for long-term tourist destination management. The information it provides can help decision makers in both the public and private sectors to improve the competitiveness of Hong Kong's tourism industry, thereby further benefiting the economic development and well-being of the local community.

\section{REFERENCES}

Alegre J, Cladera M. 2006. Repeat visitation in mature sun and sand holiday destinations. Journal of Travel Research 44 (3): 288-297.

Anderson EW, Fornell C, Lehmann DR. 1994. Customer satisfaction, market share, and profitability: Findings from Sweden. The Journal of Marketing 58 (3): 53-66.

Andreassen TW, Lervik L. 1999. Perceived relative attractiveness today and tomorrow as predictors of future repurchase intention. Journal of Service Research 2: 164-172.

Ap J. 2000. Understanding the Asian respondent when conducting tourism research: Some challenges, pitfalls and tips. In 31st Annual Conference Proceedings Travel and Tourism Research Association, Nickerson N, Mosey N, Andereck K (eds.). San Fernando Valley, CA; 282-290.

Bagozzi RP, Fornell C, Larcker DF. 1981. Canonical correlation analysis as a special case of a structural relations model. Multivariate Behavioral Research 16 (4): 437-454.

Bandura A. 2006. Guide for constructing self-efficacy scales. In Self-efficacy Beliefs of Adolescents, Pajares F, Urdan T (eds.). Information Age: Greenwich, CT; 307-337.

Chadee DD, Mattsson J. 1996. An empirical assessment of customer satisfaction in tourism. The Service Industries Journal 16 (3): 305-320.

Chan LK, Hui YV, Lo HP, Tse SK, Tso GK, Wu ML. 2003. Consumer satisfaction index: New practice and findings. European Journal of Marketing 37 (5/6): 872-909.

Chernick MR. 2007. Bootstrap Methods: A Guide for Practitioners and Researchers, $2^{\text {nd }}$ Ed. Wiley: New York.

Chin WW. 1998. Issues and opinion on structural equation modeling. MIS Quarterly, 22 (1): 7-16.

Chin WW, Gopal A. 1995. Adoption intention in GSS: Relative importance of beliefs. SIGMIS Database 26 (2-3): 42-64.

Chon K. 1990. The role of destination image in tourism: A review and discussion. Tourism Review 45 (2): 2-9.

Chon K. 1992. Self-image/destination image congruity. Annals of Tourism Research 19 (2): 360-363.

Chon K, Olsen MD. 1991. Functional and symbolic approaches to consumer satisfaction/dissatisfaction in tourism. Journal of the International Academy of Hospitality Research 28: 1-20.

Cohen P, Cohen J, Teresi J, Marchi M, Velez CN. 1990. Problems in the measurement of latent variables in structural equations causal models. Applied Psychological Measurement 14 (2): 183-196. 
Cohen JB, Fishbein M, Ahtola OT. 1972. The nature and uses of expectancy-value models in consumer attitude research. Journal of Marketing Research 9 (4): 456-460.

Correia A, Moital M, da Costa CF, Peres R. 2008. The determinants of gastronomic tourists' satisfaction: A second-order factor analysis. Journal of Foodservice 19 (3): 164-176.

Dorfman PW. 1979. Measurement and meaning of recreation satisfaction: A case study in camping. Environment and Behavior 11 (4): 483-510.

Duke CR, Persia MA. 1996. Consumer-defined dimensions for the escorted tour industry segment. Journal of Travel \& Tourism Marketing 5 (1): 77-99.

Ekinci Y. 2002. A review of theoretical debates on the measurement of service quality: Implications for hospitality research. Journal of Hospitality \& Tourism Research, 26 (3): 199-216.

Eklöf JA, Westlund, AH. 2002. The pan-European customer satisfaction index programme Current work and the way ahead, Total Quality Management \& Business Excellence, 13 (8): 1099-1106.

Fornell C. 1992. A national customer satisfaction barometer: The Swedish experience. Journal of Marketing 56 (1): 6-21.

Fornell C, Bookstein FL. 1982. Two structural equation models: LISREL and PLS applied to consumer exit-voice theory. Journal of Marketing Research 19 (4): 440-452.

Fornell C, Cha J. 1994. Partial least squares. In Advanced Methods of Marketing Research, Bagozzi RP (eds.). Blackwell: Cambridge, MA; 52-78.

Fornell C, Johnson MD, Anderson EW, Cha J, Bryant BE. 1996. The American customer satisfaction index: Nature, purpose, and findings. Journal of Marketing 60 (4): 7-18.

Fornell C, Larcker DF. 1981. Evaluating structural equation models with unobservable variables and measurement error. Journal of Marketing Research 18 (1): 39-50.

Fuchs M, Weiermair K. 2004. Destination benchmarking: An indicator-system's potential for exploring guest satisfaction. Journal of Travel Research 42(3): 212-225.

Grönroos C. 1984. A service quality model and its marketing implications. European Journal of Marketing 18 (4): 36-44.

Hirschman AO. 1970. Exit, Voice, and Loyalty: Responses to Decline in Firms, Organizations, and States. Harvard University Press: Cambridge, MA.

Hong Kong Tourism Board (HKTB). 2010. Visitor Profile Report - 2009. Hong Kong: HKTB.

Hsu CHC. 2000. Determinants of mature travelers' motorcoach tour satisfaction and brand loyalty. Journal of Hospitality \& Tourism Research 24 (2): 223-238.

Hsu CHC. 2003. Mature motorcoach travelers' satisfaction: A preliminary step toward measurement development. Journal of Hospitality \& Tourism Research 27 (3): 291309.

Hsu CH, Wong KK, Masuyama Y. 2003. Senior travelers' hotel choice and satisfaction: An investigation based on country of origin. Review of Business Research 1 (2): 159-169.

Johnson MD, Anderson EW, Fornell C. 1995. Rational and adaptive performance expectations in a customer satisfaction framework. Journal of Consumer Research 21 (4): $28-40$.

Johnson MD, Fornell C. 1991. A framework for comparing customer satisfaction across individuals and product categories. Journal of Economic Psychology 12 (2): 267-286. 
Johnson MD, Gustafsson A, Andreassen TW, Lervik L, Cha J. 2001. The evolution and future of national customer satisfaction index models. Journal of Economic Psychology 22 (2): 217-245.

Knutson BJ, Singh AJ, Yen H, Bryant BE. 2003. Guest satisfaction in the U.S. lodging industry using the ACSI model as a service quality scoreboard. Journal of Quality Assurance in Hospitality \& Tourism 4 (3\&4): 97-118.

Kozak M. 2001. Comparative assessment of tourist satisfaction with destinations across two nationalities. Tourism Management 22 (4): 391-401.

Kozak M, Rimmington M. 1999. Measuring tourist destination competitiveness: Conceptual considerations and empirical findings. International Journal of Hospitality Management 18 (3): 273-283.

Lancaster K. 1971. Consumer Demand: A New Approach. Columbia University Press: New York.

LaTour SA, Peat NC. 1979. Conceptual and methodological issues in consumer satisfaction research. Advances in Consumer Research 6 (1): 431-437.

Leblanc G. 1992. Factors affecting customer evaluation of service quality in travel agencies: An investigation of customer perceptions. Journal of Travel Research 30 (4): 10-16.

Lo A. 2006. The past, present and future of hospitality and tourism higher education in Hong Kong. Journal of Teaching in Travel \& Tourism 5 (1/2): 137-166.

Oh H, Parks SC. 1997. Customer satisfaction and service quality: A critical review of the literature and research implications for the hospitality industry. Hospitality Research Journal 20 (3): 35-64.

Oliver RL. 1980. A cognitive model of the antecedents and consequences of satisfaction decisions. Journal of Marketing Research 17 (4): 460-469.

Oliver RL, Swan J E. 1989. Consumer perceptions of interpersonal equity and satisfaction in transactions: A field survey approach. The Journal of Marketing 53 (2): 21-35.

Parasuraman A, Zeithaml VA, Berry LL. 1985. A concept model of service quality and its implications for future research. Journal of Marketing 49 (3): 41-50.

Pizam A, Milman A. 1993. Predicting satisfaction among first time visitors to a destination by using the expectancy disconfirmation theory. International Journal of Hospitality Management 12 (2): 197-209.

Pizam A, Neumann Y, Reichel A. 1978. Dimensions of tourist satisfaction with a destination area. Annals of Tourism Research 5 (3): 314-322.

Reisinger Y, Turner LW. 2002. The determination of shopping satisfaction of Japanese tourists visiting Hawaii and the Gold Coast compared. Journal of Travel Research 41 (2): 167-176.

Ringle CM, Wende S, Will A. 2005 SmartPLS 2.0 M3, www.smartpls.de.

Saleh F, Ryan C. 1992. Client perceptions of hotels: A multi-attribute approach. Tourism Management 13 (2): 163-168.

Schumacker R, Lomax R. 2004. A Beginner's Guide to Structural Equation Modeling. Erlbaum: Hillsdale, NJ.

Schwarz N, Knäuper B, Hippler HJ, Noelle-Neumann E, Clark F. 1991. Rating scales: Numeric values may change the meaning of scale labels. Public Opinion Quarterly 55: $570-582$. 
Sirgy MJ. 1984. A social cognition model of consumer satisfaction/dissatisfaction: An experiment. Psychology \& Marketing 1 (2): 27-44.

Swanson SR, Kelley SW. 2001. Service recovery attributions and word-of-mouth intentions. European Journal of Marketing 35 (1): 194-211.

Temme D, Kreis H, Hildebrandt L. 2006. PLS path modeling: A software review. SFB 649 Discussion Paper 2006-084. Available at http://edoc.hu-berlin.de/series/sfb-649papers/2006-84/PDF/84.pdf (accessed 8 February 2009).

Tenenhaus M, Vinzi VE, Chatelin Y, Lauro C. 2005. PLS path modeling. Computational Statistics \& Data Analysis 48 (1): 159-205.

Yi Y. 1990. A critical review of consumer satisfaction. In Review of Marketing, Zeithaml V A (ed.). American Marketing Association: Chicago, IL; 68-123.

Yoon Y, Uysal M. 2005. An examination of the effects of motivation and satisfaction on destination loyalty: A structural model. Tourism Management 26 (1): 45-56.

Yu L, Goulden M. 2006. A comparative analysis of international tourists' satisfaction in Mongolia. Tourism Management 27 (6): 1331-1342.

Yüksel A, Yüksel F. 2001. The expectancy-disconfirmation paradigm: A critique. Journal of Hospitality \& Tourism Research 25 (2): 107-131. 